\title{
Numerical solution of solar energy absorbed in porous medium with a new approach for vapor pressure calculation and consideration of solute crystallization
} \author{
Mahmoud S. Ahmed ${ }^{3}$ \\ ${ }^{1}$ Department of Mechanical Engineering, Faculty of Eng., Assuit University, Assuit, Egypt \\ ${ }^{2}$ Mech. Eng. Department, Faculty of Eng., Al Taif University, Al Taif, Saudi Arabia \\ ${ }^{3}$ Faculty of Industrial Education, Sohag University, Sohag, Egypt
}

Sherif A. Mohamed ${ }^{1}$, Ibrahim S. Taha ${ }^{1}$, Mahmoud G. Morsy ${ }^{1}$, Hany A. Mohamed ${ }^{2}$,

\section{Email address:}

sherifadham2000@yahoo.com (S. A. Mohamed)

\section{To cite this article:}

Sherif A. Mohamed, Ibrahim S. Taha, Mahmoud G. Morsy, Hany A. Mohamed, Mahmoud S. Ahmed. Numerical Solution of Solar Energy Absorbed in Porous Medium with a New Approach for Vapor Pressure Calculation and Consideration of Solute Crystallization. American Journal of Aerospace Engineering. Special Issue: Hands-on Learning Technique for Multidisciplinary Engineering Education. Vol. 2, No. 1-1, 2015, pp. 93-105. doi: 10.11648/j.ajae.s.2015020101.18

\begin{abstract}
The goal of the study is to enhance the productivity of solar stills using an unsaturated porous medium initially saturated by salty water and using concentrating reflector. This paper concentrates only on the mathematical model for the porous medium and its solution using a finite-volume approach. The previous studies dealt with wick medium with high water content and liquid saturation in the wick medium was not determined. A physical model for the initially saturated porous medium was developed. The model takes into consideration the salt concentration in the solution, surface and internal water diffusions to humid air with vapor pressure determined from vapor mass balance. The system of transient one-dimensional differential equations was developed together with the boundaries and initial conditions. A finite-volume method was used for discretisation of the differential equations. A fully-implicit scheme was used for unsteady term discretisation while the convective terms (liquid solution, vapor and dry air) in the energy equation are handled by an upwind scheme method. The nonlinear equations are solved simultaneously by updating the coefficients matrix at one time step until the five variables converge to prescribed tolerance. Matlab was used as a programming tool. Solution of the model is obtained and discussed.
\end{abstract}

Keywords: Porous Medium, Solute Concentration, Vapor Pressure, Absorbed Solar Radiation

\section{Introduction}

The study of porous medium represents the importance in industry, drying, soil contaminants and solar still. The wick material can be used in solar still and it can be considered as a porous medium and the nature of study for porous medium is different from that of wick material. The consideration of porous medium helps to make a mathematical model of differential equations, the mathematical model gives the mass and heat transfer in porous medium also it gives the prediction for solute crystallization. Then the novel usage of porous medium is solar still applications. Then the mathematical model can be formed to know both heat and mass transfer knowledge

$\mathrm{Ni}$ et al. [1] had developed a multiphase porous media model to predict moisture transport during intensive microwave heating of biomaterials. They formulated the governing equations and boundary conditions for multiphase moisture transport. They solved the coupled equations numerically, compared the numerical results with convective "non-microwave" heating studies which were reported in their literature. Also they obtained experimental measurements of moisture loss in their study. They assessed the contribution of the convection terms to the energy equation.

Akbar and Haghi [2] studied the heat and mass transfer phenomena occurring within a carpet during combined microwave and convective drying. They analyzed the moisture, temperature, and pressure distributions generated throughout the process.

Costa et al. [3] studied porous media with high water content which can be successfully used as thermal barriers to operate under high exposure temperatures and/ or high heat 
fluxes. Modeling and simulation of thermal barriers consisting of highly humid porous media was a challenging task. Physical model needed took into account the heat transfer mechanisms, including radiation heat transfer and phase change. Liquid water and water vapor transfers were considered, including the capillary effects for the liquid phase as well as the air transfer inside the porous medium. They concluded that the mass transfer rate from the thermal barrier to the environment is controlled by the vaporization process and vapor effusion, and not by the convection mechanism.

Neale et al. [4] studied the hygrothermal analysis of buildings which is becoming increasingly utilized for evaluating heat and moisture related problems within the building envelope. They concluded that the convective surface coefficients were particularly important for calculations involving boundary layer heat and mass transfer. The convective moisture coefficients were often calculated through analogy equations, i.e. Lewis and Chilton Colburn ones. However, these equations were not always valid. Therefore, a different approach is needed to accurately determine heat and mass convection coefficients. Murugesan et al. [5] studied numerically the evaporative drying of a twodimensional rectangular brick. Average heat and mass transfer coefficients appropriate to the conjugate problem were defined based on constant temperature and moisture differentials between the solid and the ambient. Free convection effects on drying were also studied for some initial period for low Reynolds number. It was demonstrated that heat and mass transfer coefficients based on constant temperature and moisture potentials may be more representative of the conjugate heat and mass transfer process during drying. Hence, the conjugation of two coefficients is less representative based on instantaneous temperature difference and moisture difference.

Lee et al. [6] developed a transient two-dimensional mathematical model to simulate the through-air drying process for tufted textile materials. The heat and mass transfer in cylindrical porous medium and air flowing around it were analyzed separately. The resulting system of the three non-linear differential equations was numerically solved by an implicit finite-difference method. Duc Le et al. [7] solved the salt concentration equations in conjunction with the liquid saturation evolution in space and time using numerical and analytical methods for selected cases. The main objective of their study was to combine the advances in the understanding of flow-through evaporation from porous media with solute transport theory and develop a better understanding of evolution of crystallized salt saturation in rocks. The mass of solid salt crystallized was calculated by applying solubility limits on the liquid concentrations for the case of fast crystallization kinetics and capillary-dominated conditions. Koniorczyk and Gawin [8] had taken the salt phase change kinetics into account during the modeling of coupled moisture, salt, and heat transport. Their mathematical model was describing moisture and salt transport in non-isothermal conditions. The process of salt phase change in the pore solution was modeled using the non-equilibrium approach, where the rate law describing mass change of the crystallized salt is known.

The previous works of wicked solar still did not deal with internal structure of porous media, solar irradiance penetration, utilization of drying period of porous media, crystallization inside pores and effect of partial saturation of the porous medium. However, the studying of heat and mass transfer is considered a surface phenomenon. A porous medium, being a heterogeneous system made of a solid matrix with its void filled with fluids, can be treated as a continuum by properly accounting for the role of each phase in transport through this system of phases [9]. In the previous work of porous medium, the vapor pressure is not taken as a variable in the differential Equations. However, it was not calculated as a variable in the differential equations and the source and sink terms were canceled each other by summing the liquid and vapor mass equations. In the present study, a new approach is presented by calculating the vapor partial pressure using suggested an evaporation model to calculate the vapor source term in the mass vapor equation. Also, the solar radiation attenuation is modeled in the present work to calculate an absorbed solar radiation at the porous medium different layers. Five one-dimensional differential equations expressing mass, momentum and energy equations are presented in five unknowns $\left(S, C, P, P_{v}\right)$. The nonlinear equations are solved simultaneously by updating the coefficients matrix at one time step until the five variables converge to prescribed tolerance. The numerical code is written in Matlab. Solution of the mathematical model is obtained and discussed.

\section{Physical Model}

Figure 1 shows the system of the current work. The porous material is supposed rigid and unsaturated one with capillary behavior. Mass and heat transfers are supposed to be one dimensional. The closed side $(\mathrm{z}=0)$ of material is adiabatic and the open side $(\mathrm{z}=\mathrm{L})$ is subjected to natural convective flow and long wave radiation. The solar radiation $(\lambda=0.3-3.0 \mu \mathrm{m})$ penetrates the porous material and it is absorbed by fluid and solid phases. The model considered in this paper is only that in the porous medium. Figure 2 shows the schematic sketch of porous medium phases.

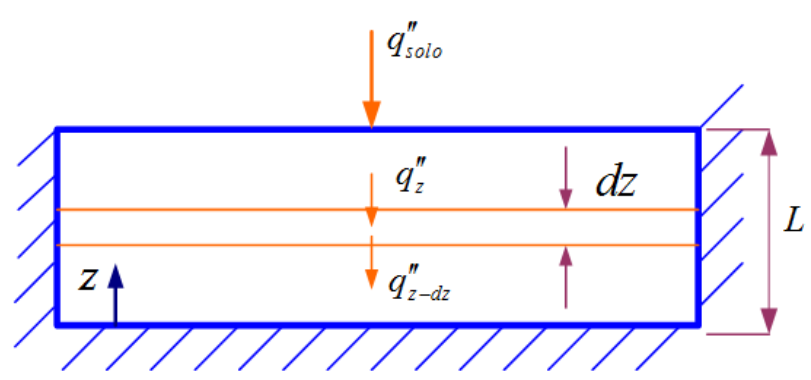

Fig 1. System of porous medium with absorbed solar energy 


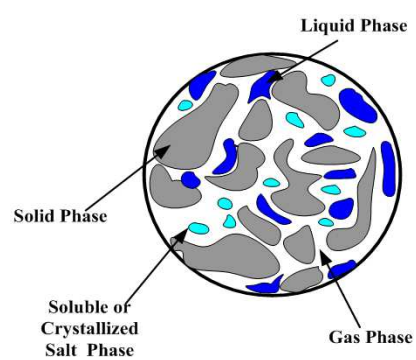

Fig 2. Physical model of non-hygroscopic porous medium

\subsection{Assumptions}

1. The skeleton of a porous body is a rigid solid which does not swell, absorb water, or dissolve in water and does not enter into chemical interactions with water solution (water/ $\mathrm{NaCl}$ solution)

2. The moisture adsorbed due to hygroscopicity of salt is neglected.

3. Transport in the material is simplified by making local thermal equilibrium.

4. The salt movement occurs by convection and Fickian's diffusion.

5. The effects of the salt crystallization on the moisture and ionic transport are taken into account by correcting the material transport properties as a function of the porosity in each time step.

6. The specific heat of the brine is assumed to be dependent on brine concentration.

7. The materials of the porous medium are treated as being continuous and having properties defined everywhere in space.

8. The porous material is homogeneous and isotropic.

9. The gas-phase is ideal in the thermodynamic sense.

10. The vapor mass is transferred by diffusion from porous medium to ambient.

11. The scattering from reflection in a porous medium bed is neglected.

\subsection{Attenuation of Solar Radiation inside Porous Medium}

The porous medium is assumed to be a semitransparent medium for solar energy which in turn is diffuse radiation. Internal reflection and scattering are neglected and only absorption is taken into consideration. At any location $\mathrm{z}$, the change in radiation flux for the element, as a result of absorption, is a function of the flux reaching the element [10]. The change in intensity has been found experimentally to depend on the magnitude of the local intensity. If a coefficient of proportionality $\gamma$ which depends on the local properties of the medium is introduced, then the decrease in solar flux in an element volume is given by:

$$
\left.\begin{array}{l}
d q^{\prime \prime}(z, t)=q_{z}^{\prime \prime}-q_{z-d z}^{\prime \prime} \\
d q^{\prime \prime}(z, t)=+\gamma_{\text {eff }}(z) q^{\prime \prime}(z, t) d z
\end{array}\right\}
$$

The quantity $\gamma_{\text {eff }}$ is called the effective absorption coefficient of the material in the element layer which takes into consideration the absorption in the different components of the porous medium of element thickness $d z$. The absorption coefficient is a physical property of the material and has the units of reciprocal length as it is a volumetric property. The value of $\gamma_{\text {eff }}$ is dependent on $\mathrm{t}$ and $\mathrm{z}$ as do the different component of the porous medium. The radiation flux along the path is attenuated exponentially while passing through an absorbing porous medium. The boundary conditions are:

$$
\text { at } \left.\mathrm{z}=\mathrm{L}, q_{z}^{\prime \prime}=q_{\text {solo }}^{\prime \prime}\right\}
$$

Where:

$q_{\text {solo }}^{\prime \prime}$ is the solar flux impinging on the top surface.

The solution is hence given by:

$$
q^{\prime \prime}(z, t)=q_{\text {solo }}^{\prime \prime} \exp ^{-\gamma_{e f f}(L-z)}
$$

The energy absorbed by an elemental volume per unit volume is thus equal to $\frac{\partial q_{z}^{\prime \prime}}{\partial z}$ or

$$
q_{z}^{\prime \prime \prime}=q_{\text {solo }}^{\prime \prime} \gamma_{\text {eff }} \exp ^{-\gamma_{e f f}(L-z)}
$$

The latter term is considered as energy generation term in the energy equation of the porous medium. The radiation flux reaching the bottom of the porous medium is assumed to be absorbed at the bottom surface $(\mathrm{z}=0)$ of the container holding the porous medium. The latter term is equal to:

$$
q_{\text {sol }}^{\prime \prime}(0, t)=q_{\text {solo }}^{\prime \prime}(t) \exp ^{-\gamma_{\text {eff }} L}
$$

\subsubsection{Calculation of the Absorption Coefficient for Porous Medium Phases}

The absorption coefficients for porous medium phases (solid, solution, gas) are functions of wavelength distribution. Thus, the total absorption coefficient for each phase of the porous medium is calculated from:

$$
\gamma_{\text {phase }}=\frac{\int_{0.3}^{3.0} E_{\lambda} \gamma_{\lambda} d \lambda}{\int_{0.3}^{3.0} E_{\lambda} d \lambda}
$$

$\gamma_{\text {phase }}$ is the medium phase total (average) absorption coefficient $m^{-1}, \gamma_{\lambda}$ the medium phase spectral absorption coefficient, $m^{-1}, E_{\lambda}$ spectral intensity $W^{-2} / \mu m, \lambda$ is the solar irradiance wavelength, $\mu \mathrm{m}$.

The effective absorption coefficient is the volume average of absorption coefficient of all components of porous medium, or

$$
\gamma_{\text {eff }}=\left(\phi S_{l} \gamma_{l}+\phi w_{v} S_{v} \gamma_{v}+\phi S_{p} \gamma_{s a l}+(1-\phi) \gamma_{s}\right)
$$


Where, $\gamma_{l}$ is the water average absorption coefficient, $\gamma_{v}$ is the vapor average absorption coefficient, $\gamma_{s}$ is the sand average absorption coefficient, $\gamma_{\text {sal }}$ is the salt average absorption coefficient.

The liquid water average absorption coefficient is calculated from the data of spectral absorption coefficient which is reported in [11]. Thus, the calculated average value is $350 \mathrm{~m}^{-1}$. The water vapor absorption coefficient is calculated from the spectral absorption coefficient and the calculated average value is approximately $10 \mathrm{~m}^{-1}$ [12] There is a little amount of carbon dioxide which is included to air components. Thus, the larger components of air are nitrogen and oxygen which have no absorption for solar energy. There is no data for absorption coefficient for sand and because $90 \%$ of glass is made of sand, the sand absorption coefficient was assumed to be equal the double of that of glass. Glass absorption coefficient is approximately 30 $m^{-1}$ [10] and thus that of glass is taken $60 \mathrm{~m}^{-1}$. The absorption coefficient of $\mathrm{NaCl}$ is $0.0007 \mathrm{~m}^{-1}$ [13] at wavelength of $1.06 \mu \mathrm{m}$. The total average absorption coefficient of $\mathrm{NaCl}$ is assumed $0.0007 \mathrm{~m}^{-1}$ through the solar wavelength band since no data is available at other wavelength values.

\subsection{Water Vapor Diffusion inside Porous Medium}

The vapor pressure is estimated from vapor mass balance and it is solved simultaneously with other four variables. The vapor mass transfer inside the porous medium consists of capillary mass rate, diffusion mass rate through gas (humid air) and evaporation mass rate by diffusion from water solution to porous medium humid air.

\subsubsection{Diffusion of Vapor from Water to Solution to Gas}

To calculate the mass rate of diffusion from water solution to vapor inside the porous medium, it is assumed that the salt solution in an element volume that has the profile of $\mathrm{N}$ cylindrical columns each of diameter (d) surrounded by a volume of gas making cylindrical annulus of outer diameter $(d+y)$. The value of $y$ represents the air space around water cylinder and was considered to be $0.0075 \mathrm{~m}$. Thus, diffusion of water solution to humid air occurs from cylindrical surface areas to the surrounding air. The equations for mentioned evaporation model are as follows:

$$
\begin{gathered}
A_{c r} \phi S_{g}=N\left(\frac{\pi}{4}\left((d+y)^{2}-d^{2}\right)\right) \\
A_{c r} \phi S_{l}=N \frac{\pi}{4} d^{2}
\end{gathered}
$$

From equations 8,9 , the following two equations are derived

$$
N=\frac{4 A_{c r} \phi S_{l}}{\pi d^{2}}
$$

$$
d^{2}-\left(\frac{2 y S_{l}}{S_{g}}\right) d-\left(\frac{S_{l}}{S_{g}} y^{2}\right)=0
$$

The values of $\mathrm{N}$ and $\mathrm{d}$ can be obtained from equations (10) and (11). Since the temperature distribution is one dimensional, evaporation takes place by diffusion from saturated air at the surface of water to the unsaturated surrounding air at the same temperature. The rate of vapor mass diffused from water columns to the surrounding air per unit volume of the porous medium is calculated from:

$$
\dot{m}_{\text {evap }}^{\prime \prime \prime}=A_{s r} h_{m p}\left(\rho_{v s}-\rho_{v}\right) / d z
$$

Where:

$A_{s r}$ is the ratio of water solution surface area $A_{l s}$ to crosssection area of porous medium $A_{c r}$ and $h_{m p}$ is the mass transfer coefficient between solution surface and humid air. The liquid solution surface area is given by:

$$
A_{l s}=N \pi d(d z)=A_{s r} A_{c r}
$$

and from eq. (9)

$$
\left.\begin{array}{rl}
\frac{N \pi d}{A_{c r}} & =S_{l} \phi \frac{4}{d} \\
\therefore A_{s r} & =\frac{N \pi d(d z)}{A_{c r}}=S_{l} \phi \frac{4}{d}(d z)
\end{array}\right\}
$$

Hence,

$$
\therefore \dot{m}_{\text {evap }}^{\prime \prime \prime}=S_{l} \phi \frac{4}{d} h_{m p}\left(\rho_{v s}-\rho_{v}\right)
$$

The mass transfer coefficient $h_{m p}$ is calculated from [14]:

$$
\begin{aligned}
& h_{m p}=S h * D_{\text {efg }} / d z \\
& S h=0.59(G r * S c)^{0.25}\left(10^{5}<G r * S c<10^{9}\right) \\
& S h=0.1 *(G r * S c)^{1 / 3}\left(10^{9}<G r * S c<10^{13}\right) \\
& \text { where, } \\
& \begin{array}{l}
G r=g\left(\rho_{h a, s}-\rho_{h a}\right) L_{c}^{3} / \frac{\left(\rho_{h a, s}+\rho_{h a}\right)}{2} v_{a} \\
S c=v_{a} / D_{e f g}
\end{array}
\end{aligned}
$$

The characteristic length $L_{c}$ in eq. (16) is taken $(y / 2)$.

\subsubsection{Vapor Mass Transfer from Inside Porous Medium by Capillary and Diffusion}

The total flux of vapor is composed of convective (Darcy flow) and diffusion flows respectively as these are given by the following equation [1]:

$$
\dot{m}_{v}^{\prime \prime}=\left(-\rho_{v} \frac{K K_{r, g}}{\mu_{g}} \frac{\partial P}{\partial z}-\frac{C_{g}^{2}}{\rho_{g}} M_{a} M_{v} D_{e f f} \frac{\partial\left(P_{v} / P\right)}{\partial z}\right)
$$




\subsection{Soluble and Crystallized Salt Model}

There are two approaches for salt crystallization; namely, equilibrium approach and kinetic approach. In the first approach the equilibrium between the dissolved and precipitated salt is assumed. The amount of precipitated salt in the pores is defined by its saturation degree $\mathrm{Sp}$, which is described by the salt binding isotherms. In this approach, it is assumed that salt solution is not saturated. Due to the physical adsorption, some of ions are captured by the solid skeleton surface [15]. In kinetic approach, it is assumed that there is no salt in the solid phase until the solution solubility limit $C_{\text {sat }}$ (i.e. the salt mass concentration of the saturated solution at its temperature) is reached. After exceeding the maximum salt concentration, the solution is supersaturated. The supersaturation ratio (i.e. current concentration/concentration at saturation), the supersaturation is the driving force of the salt crystallization, which starts when the solution supersaturation ratio is greater than one. The first crystals are formed on the crystallization nuclei which are usually built by dust or other contaminations. An increase of solid salt mass is calculated on the basis of the supersaturation ratio, according to the following equation [15]:

$$
\begin{gathered}
\frac{d S_{p}}{d t}=\left\{\begin{array}{l}
S_{l} K\left(C_{s}-A^{\prime} C_{s a t}\right)^{p}, \mathrm{C}_{\mathrm{s}} \geq A^{\prime} C_{s a t} \\
-S_{l} K\left|C_{s}-A^{\prime} C_{s a t}\right|^{p}, \mathrm{C}_{\mathrm{s}}<A^{\prime} C_{s a t}
\end{array}\right. \\
\dot{m}_{\text {prece }}^{\prime \prime \prime}=\left(-\rho_{p} K^{\prime}\right)\left(S_{l}\left(C_{s}-A^{\prime} C_{s, s a t}\right)\right)
\end{gathered}
$$

In equation (18), it is assumed that there is no salt in the solid phase until reaches the solution solubility limit $C_{\text {sat }}$ (i.e. the salt mass concentration of the saturated solution at a current temperature) is reached. After exceeding the maximum salt concentration, the solution is supersaturated. Equation (19) represents the precipitated salt mass when the solution is supersaturated. An increase of solid salt mass is calculated on the basis of the supersaturation ratio, according to equation (18). The process order, $p$, depends on the properties of porous body and the kind of salt [8]. There is a need to determine mass of precipitated solute in the solution (dissolved salt) or a mass crystallized solute. An increase of the mass of dissolved solute has a negative sign which physically means dissolution of salt crystals. It was found from the experiments that the form of rate law and the order of the process $p=1.9$ was taken from previous work, where the salt crystallization in bricks was analyzed. The other constants of the rate law were assumed arbitrary due to the lack of the experimental data concerning cement mortar and the rate constant of crystallization of sodium chloride is given at [15].

\subsection{Ambient Temperature and Humidity Calculation Method}

The ambient temperature was assumed to be correlated as a cosine wave with time with a maximum at 3 p.m. and minimum at 3 a.m. The maximum and minimum temperatures are usually obtained from the meteorological data for different locations (Assuit city was considered for the current study). The relative humidity is known at 3 p.m. for Assuit. The humidity ratio is assumed to be constant during the day. These assumptions help in estimating the temperature and relative humidity of air at any time during the day. The data of Assuit, Egypt are used in this study.

\section{Equilibrium State Laws and Properties}

The input data are shown at table (1)

The total porous medium volume is:

$$
\Delta V=\Delta V_{s}+\Delta V_{w}+\Delta V_{g}+\Delta V_{p}
$$

The porosity is:

$$
\phi=\frac{\Delta V_{w}+\Delta V_{g}+\Delta V_{p}}{\Delta V}
$$

The water saturation, gas saturation and salt crystallized saturation are defined as:

$$
\begin{gathered}
\left.S_{l}=\frac{\Delta V_{w}}{\phi \Delta V}, S_{g}=\frac{\Delta V_{g}}{\phi \Delta V}, S_{p}=\frac{\Delta V_{p}}{\phi \Delta V}\right\} \\
S_{l}+S_{g}+S_{p}=1
\end{gathered}
$$

The mass density of water vapor and dry air and their mixture are:

$$
\left.\begin{array}{l}
\rho_{v}=\frac{P_{v}}{R_{v} T}, \rho_{a}=\frac{P_{a}}{R_{a} T} \\
\rho=\rho_{v}+\rho_{a}, P=P_{v}+P_{a}
\end{array}\right\}
$$

The intrinsic permeability is given by [16]:

$$
K(\phi)=K_{0}\left(\frac{\phi\left(1-S_{p}\right)}{\phi}\right)^{3}\left(\frac{1-\phi}{1-\phi\left(1-S_{p}\right)}\right)^{2}
$$

The effective gas diffusion coefficient is given by [1]:

$$
D_{i}(\phi)=D_{i}^{0}\left(\phi\left(1-S_{l}-S_{p}\right)\right)^{\frac{4}{3}}
$$

The effective salt diffusion coefficient is given by [17]:

$$
D_{\text {sal }, e f}=S_{l}^{2 / 3}\left(0.779+0.027 T+3 \times 10^{-4} T^{2}\right) \times 10^{-9}
$$

The capillary pressure is given by [9]:

$$
\left\langle P_{c}\right\rangle=\frac{\sigma}{(K / \phi)^{\frac{1}{2}}}\left(0.364\left(1-e^{-40\left(1-S_{l}\right)}\right)+0.221\left(1-S_{l}\right)+\frac{0.005}{S_{l}-0.08}\right)
$$

The capillary diffusivity is given by [1]:

$$
D_{w}=\left(\frac{K_{r l} K}{\mu_{l}} \frac{\partial P_{c}}{\partial S_{l}}\right)
$$


The liquid viscosity, thermal conductivity, and surface tension are given by [18]:

$$
\begin{gathered}
\mu_{l}=2.1 \times 10^{-6} \exp \left(\frac{1808.5}{T}\right)\left(1+1.85 C_{s}-4.1 C_{s}^{2}+44.5 C_{s}^{3}\right) \\
K_{l}=0.04 C+K_{w} \\
\sigma=\left(0.03059 \exp \left(\frac{252.93}{273.15+T}\right)+0.04055 C_{s}\right)
\end{gathered}
$$

The liquid density is given by [19]:

$$
\left.\begin{array}{l}
\rho_{l}=\rho_{o}(1+\varepsilon C) \\
\varepsilon=0.7558
\end{array}\right\}
$$

Relative permeability [9]:

$$
\left.\begin{array}{l}
S_{e f f}=\frac{S_{l}-S_{i r}}{1-S_{i r}} \quad S_{e f f} \leq 1 \\
K_{r l}=S_{e f f}^{3} \\
K_{r g}=\left(1-S_{e f f}\right)^{3}
\end{array}\right\}
$$

The effective heat capacity and thermal conductivity:

$$
\begin{aligned}
& \left(\rho C_{p}\right)_{e f f}=\left(\phi \delta_{l} \rho_{l} C_{p, l}+\phi\left(1-S_{l}-S_{p}\right) \rho_{v} C_{p, v}+\phi\left(1-S_{l}-S_{p}\right) \rho_{a} C_{p, a}+\phi S_{p} C_{p, c r}+(1-\phi) \rho_{s} C_{p, s}\right) \\
& K_{e f f}=\left(\phi\left(1-w_{v}\right)\left(1-S_{l}-S_{p}\right) K_{a}+\phi w_{v}\left(1-S_{l}-S_{p}\right) K_{v}+\phi \oint_{l} K_{l}+\phi \phi_{p} K_{c r}+(1-\phi) K_{s}\right)
\end{aligned}
$$

Where:

$C_{p l}=4180-4.396(C / 100) \rho_{l}+0.0048(C / 100)^{2} \rho_{l}^{2}[20],\left(\rho C_{p}\right)_{e f f}$ is the porous medium effective heat capacity, $K_{\text {eff }}$ is the effective thermal conductivity of porous medium components, $C_{p l}$ is liquid solution specific heat, $K_{l}$ is the liquid solution thermal conductivity.

\section{Mass and Heat Transfer}

Transport in the material is simplified by making the assumption of local thermal equilibrium. This means that at any cross section, the solid, liquid, gas and precipitated salt phases are at the same temperature. This allows the thermal transport to be characterized by a single equation for conservation of energy. Heat transfer model includes conduction, radiation, enthalpy convection, sensible heating and phase change. The partially saturated media raises liquid water solution by capillary action. There is a phase change for liquid water and soluble salt. For the liquid water is being evaporated by diffusion for some periods of time, the salt concentration increases to reach the supersaturation condition. When supersaturation occurs, the salt will be crystallized at dry region of porous media. A realistic model is considered at the exposed boundary in what concerns mass transfer and the outflow mass transfer of vapor is dictated by convective diffusion.

\subsection{Governing Equations of Heat and Mass Transfer}

The mass and energy conservations are given by the following five equations:

$$
\begin{aligned}
& \phi \frac{\partial}{\partial t}\left(\rho_{l} S_{l}\right)+\dot{m}_{e v p}^{\prime \prime \prime}=-\left(\frac{\partial}{\partial z}\left(-\rho_{l} \frac{K K_{r, l}}{\mu_{l}}\left(\frac{\partial P_{l}}{\partial z}-\rho_{l} \vec{g}\right)\right)\right) \\
& \phi \frac{\partial}{\partial t}\left(\rho_{v} S_{g}\right)-\dot{m}_{\text {evp }}^{\prime \prime \prime}=-\frac{\partial}{\partial z}\left(\begin{array}{l}
-\rho_{v} \frac{K K_{r, g}}{\mu_{g}} \frac{\partial P}{\partial z} \\
-\frac{C_{g}^{2}}{\rho_{g}} M_{a} M_{v} D_{e f f} \frac{\partial\left(P_{v} / P\right)}{\partial z}
\end{array}\right) \\
& \phi \frac{\partial}{\partial t}\left(\rho_{l} C_{s} S_{l}+\rho_{p} S_{p}\right)=-\frac{\partial}{\partial z}\left(\begin{array}{l}
-\rho_{l} C_{s} \frac{K K_{r, l}}{\mu_{l}}\left(\frac{\partial P_{l}}{\partial z}-\rho_{l} \vec{g}\right) \\
-\phi \rho_{l} S_{l} D_{s a l} \frac{\partial C_{s}}{\partial z}
\end{array}\right) \\
& \phi \frac{\partial}{\partial t}\left(S_{g} \rho_{a}\right)=-\frac{\partial}{\partial z}\left(\begin{array}{l}
-\rho_{a} \frac{K K_{r, g}}{\mu_{g}} \frac{\partial P}{\partial z} \\
-\frac{C_{g}^{2}}{\rho_{g}} M_{v} M_{a} D_{e f f} \frac{\partial\left(P_{a} / P\right)}{\partial z}
\end{array}\right)
\end{aligned}
$$

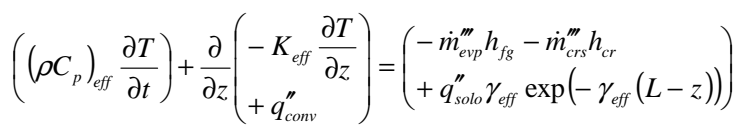

The mass balance equation (37) describes the liquid solution mass transfer. The salt solution leaves the volume across its boundary due to flow moving at Darcy's velocity and takes into consideration gravity force. The mass balance represented by equation (38) describes the vapor mass transfer. The mass balance equation (39) represents the solute mass transfer. The first (LHS) term represents the stored solute and the second term represents the precipitated salt which results from dissolution or crystallization. The mass balance equation (40) describes the dry air mass transfer. Fick's law governs mass fluxes due to concentrations gradients (diffusion part) which are often the most significant driving force as shown in equations (38), (39) and (40). The modified Navier-Stokes equation for porous media reduces to Darcy's equation inside the porous media for lowpermeability systems [21]. The Darcy's velocity is applied at mass balance equations (37), (38), (39) and (40). The energy balance, equation (41), describes heat transfer inside porous medium. The first (LHS) term is the storage term; the second is the net conduction and convection flux of fluid phases (solution+ vapor+ air). The (RHS) term is the local absorbed solar energy per unit volume. The convection term in the energy equation is defined by the following equation,

$$
-\frac{\partial q_{c o n v}^{\prime \prime}}{\partial z}=\left(C_{p v} \overrightarrow{\dot{m}}_{v}^{\prime \prime}+C_{p a} \overrightarrow{\dot{m}}_{a}^{\prime \prime}+C_{p l} \overrightarrow{\dot{m}}_{l}^{\prime \prime}\right) \frac{\partial T}{\partial z}
$$




\subsection{Initial and Boundary Conditions}

\subsubsection{Initial Condition}

$$
\left.\begin{array}{l}
S(z, 0)=S_{i} \\
C(z, 0)=C_{i} \\
P(z, 0)=P_{i} \\
T(z, 0)=T_{i} \\
P_{v}(z, 0)=P_{v i}
\end{array}\right\}
$$

Where:

$S_{i}, C_{i}, P_{i}, T_{i}$, and $P_{v i}$ are the saturation, solute concentration, pressure, temperature, and concentration respectively at time zero.

\subsubsection{Boundary Conditions}

The bottom (closed) and top (open) boundaries are given as follows:

\subsubsection{Closed Boundary Conditions}

$$
\left.\begin{array}{l}
\text { At } \mathrm{z}=0, \\
\dot{m}_{l}^{\prime \prime}=0 \\
\dot{m}_{v}^{\prime \prime}=0 \\
\dot{m}_{s a l t}^{\prime \prime}=0 \\
\dot{m}_{a}^{\prime \prime}=0
\end{array}\right\}
$$

The energy balance at closed boundary is given by:

$$
\left(-K_{\text {eff }} \frac{\partial T}{\partial z}\right)=q_{\text {solo }}^{\prime \prime} \exp \left(-\gamma_{\text {eff }} L\right.
$$

\subsubsection{Open boundary Condition}

$$
\text { At } \mathrm{z}=\mathrm{L}
$$

It is assumed that $P=P_{a m b}, P_{a m b}$ is the ambient pressure. The mass balance for liquid, and vapor are given by:

$$
\left.\begin{array}{l}
\dot{m}_{l}^{\prime \prime}=\dot{m}_{\text {evap } 1}^{\prime \prime} \\
\dot{m}_{v}^{\prime \prime}=\dot{m}_{\text {evap } 2}^{\prime \prime} \\
\dot{m}_{\text {salt }}^{\prime \prime}=0
\end{array}\right\}
$$

Where:

$\dot{m}_{\text {evap } 1}^{\prime \prime}$ is mass flux diffused from solution surface to ambient air, and $\dot{m}_{\text {evap } 2}^{\prime \prime}$ is mass flux diffused from inner volume humid air to ambient air at surface. The two mentioned fluxes are calculated from:

$$
\left.\begin{array}{l}
\dot{m}_{\text {evap } 1}^{\prime \prime}=\left(\phi S_{l} h_{m l v}\left(\rho_{v, s a t}-\rho_{a m b}\right)\right) \\
\dot{m}_{\text {evap } 2}^{\prime \prime}=\dot{m}_{v D}^{\prime \prime}
\end{array}\right\}
$$

$$
\dot{m}_{v, D}^{\prime \prime}=\frac{2}{\Delta z}\left(\begin{array}{l}
\left(\frac{P M_{v} M_{a} D_{e f f}}{R T\left(M_{v} P_{v}+M_{a}\left(P-P_{v}\right)\right)}\right)_{N}\left(P_{v, N}-P_{v, h a}\right) \\
+\left(-\frac{M_{v} M_{a} D_{e f f} P_{v}}{R T\left(M_{v} P_{v}+M_{a}\left(P-P_{v}\right)\right)}\right)_{N}\left(P_{N}-P_{h a}\right)
\end{array}\right)
$$

$h_{m l v}$ is the mass transfer coefficient for vapor diffusion from porous medium to ambient, $\dot{m}_{v D}^{\prime \prime}$ is mass vapor diffusion from humid air in porous medium's surface to humid air region, $h_{m l v}$ is calculated from [14],

$$
h_{m l v}=\frac{h c}{\rho_{a}}\left(\frac{D_{e f g}}{\alpha}\right)^{\frac{2}{3}}
$$

It is assumed that the vapor mass is transferred from porous medium and vapor mass is diffused from porous medium surface to ambient. Wherever the liquid mass is reached to porous medium surface by capillary action, the diffused surface liquid is compensated by it. The water vapor mass transfer coefficient from porous medium to ambient is unknown and there is no experimental data for its value. However, the boundary node for vapor mass transfer is taken as shown in Fig. 3 [22].

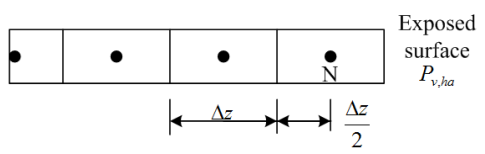

Fig 3. The boundary element for vapor mass transfer

The energy balance at open boundary is given by:

$$
\text { Energy flux in = Energy flux out }
$$

Figure 4 shows the energy fluxes at open surface boundary.

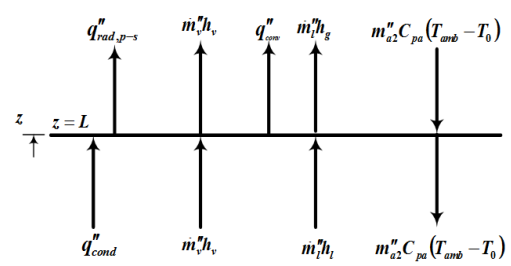

Fig. 4. Open surface energy boundary condition

The heat fluxes enter the top boundary are:

$q_{\text {cond }}^{\prime \prime}$ the conduction heat flux

$\dot{m}_{l}^{\prime \prime} h_{l}$ the enthalpy flux of liquid

$\dot{m}_{\text {evp } 2}^{\prime \prime} h_{v} \quad$ the enthalpy flux of vapor diffused from gas to ambient

The energy fluxes out from the top boundary are:

$q_{\text {conv }}^{\prime \prime}$ the convection flux to ambient

$q_{\text {rad,sur-s }}^{\prime \prime}$ the radiation flux to sky

$\dot{m}_{\text {evp } 1}^{\prime \prime} h_{g}$ the enthalpy flux of vapor diffused from liquid to ambient air 
The energy balance at open boundary can be derived from:

$$
\left(-K_{\text {eff }, \text { sur }} \frac{\partial T}{\partial z}=\dot{m}_{\text {evp } 1}^{\prime \prime} h_{f g}+q_{r a d}^{\prime \prime}+q_{c o n v}^{\prime \prime}\right)
$$

Where:

$$
K_{e f f s u r}=\left(\phi\left(1-w_{v}\right)\left(1-S_{l}-S_{p}\right) K_{a}+\phi v\left(1-S_{l}-S_{p}\right) K_{v}+\phi \delta_{l} K_{l}+\phi S_{p} K_{c r}+(1-\phi) K_{s}\right)
$$

The convection and radiation fluxes are given by:

$$
\left.\begin{array}{l}
q_{c o n v}^{\prime \prime}=h_{\mathrm{c}}\left(T_{s u r}-T_{a}\right) \\
q_{r}^{\prime \prime}=f \sigma\left(T_{s u r}^{4}-T_{s}^{4}\right)
\end{array}\right\}
$$

The heat transfer coefficient from porous medium surface to ambient is given by [14]

$$
h c=N u\left(K_{a}\left(1-w_{\text {sur }}\right)+K_{v} w_{\text {sur }}\right) / L_{c}
$$

$$
\left.\begin{array}{c}
N u=0.54\left(R_{a L}\right)^{1 / 4}\left(10^{4} \leq R_{a L} \leq 10^{7}\right) \\
N u=0.15\left(R_{a L}\right)^{1 / 3}\left(10^{7} \leq R_{a L} \leq 10^{11}\right) \\
R_{a L}=\frac{g\left(\rho_{h a, s u r}-\rho_{h a, a m b}\right) L_{c}^{3}}{\left(v_{a}\left(\frac{K}{C_{p}}\right)_{h a}\right)}
\end{array}\right\}
$$

Both air and vapor properties are calculated at film temperature. Wherever, the concentration difference is between air at the porous medium surface and ambient air, the mass can be transferred from porous medium surface to ambient. Thus, the Grashof number which depends upon the density differences is applicable here [14]. Prantdl number and thermal diffusivity $\alpha$ are calculated at humid air conditions.

\section{Numerical Solution}

The finite-volume method is applied to a conservation statement for a control volume.

$$
\int_{v} \operatorname{Div} \overrightarrow{\mathrm{V}} \mathrm{d} v=\oint_{\mathrm{S}} \overrightarrow{\mathrm{V}} \bullet \hat{\mathrm{n}} \mathrm{dS}
$$

Where $v$ the volume of interest, $\mathrm{S}$ is is the boundary surface of the volume, $\vec{V}$ is a vector function with continuous first spatial derivatives within the volume, and $n$ is the unit vector normal to the surface oriented to the positive pointing outward from the volume. In Eq. 54, the integral on the left is evaluated over the control volume, which may be a one-, two-, or three-dimensional region, whereas the integral on the right is a contour integral to be evaluated over the boundaries of the control volume [23]. The finite-volume method is applied to a conservation statement for a control volume. A finite-volume method was used for discretisation of the differential equations. A fullyimplicit scheme was used for unsteady term discretisation while the convective terms (liquid solution, vapor and dry air) in the energy equation are handled by an upwind-scheme method. The system of equations is solved by direct method (inverse matrix). The coefficients matrix (K-coefficients) is a function of five dependent variables (liquid saturation, salt solution concentration, gas pressure, temperature, vapor pressure). The nonlinear equations are solved simultaneously by updating (iteration using new solution of variables) the coefficients matrix at one time step until the five variables converge to prescribed tolerance. The numerical code is written in Matlab. The K-coefficients are calculated by an arithmetic average at the interfaces [24]. The convergence is ensured by five convergence criteria for the variables. Figure 5 shows a flow chart for the program designed for numerical solution.

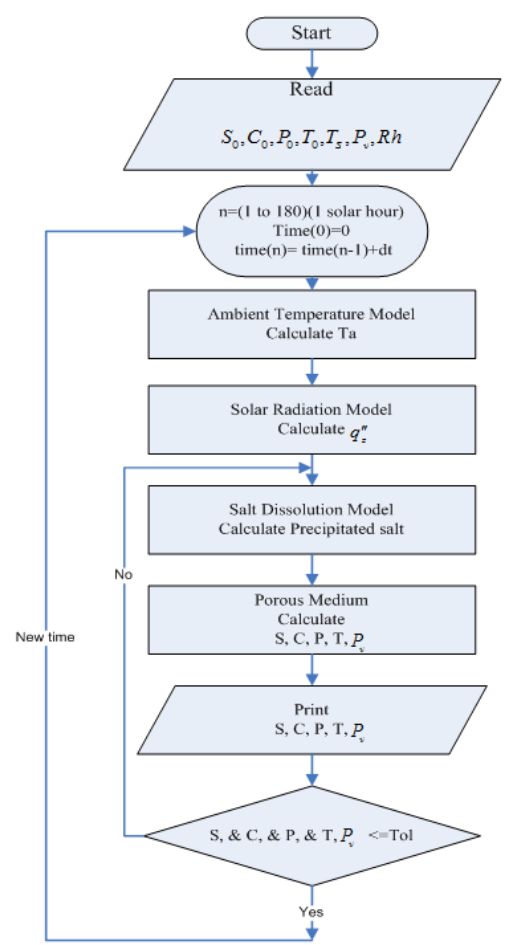

Fig 5. Programming flow chart.

\subsection{Time Step and Number of Nodes}

The convergence is occurred at time step of 20 seconds. Another time step is used when the vapor pressure equation is unstable for high evaporation rate and the second time step is 10 seconds. The number of nodes was found to be 31 which, gives the best results with selected time steps. The mass of different phases that were calculated for the porous medium, were checked at the end of each interval; also, the energy balance for the porous medium was checked for each time interval to release the convergence criteria by under and over relaxation. The liquid solution mass reduction and masses of water vapor and solute are given respectively by the following equations: 


$$
\left.\begin{array}{c}
\text { mass }_{l}=\left.\left(\sum_{1}^{N} \rho_{l} \phi S_{l} \Delta z A_{c r}\right)\right|_{t_{2}}-\left.\left(\sum_{1}^{N} \rho_{l} \phi S_{l} \Delta z A_{c r}\right)\right|_{t_{1}} \\
\operatorname{mass}_{v}=\int_{t_{1}}^{t_{2}}\left(m_{\text {evp } 1}+m_{\text {evp } 2}\right) A_{c r} d t \\
\left.m_{\text {solute }}\right|_{t=0}=\sum_{1}^{N} C \rho_{l} S \phi A_{c r} z \\
\left.m_{\text {solute }}\right|_{t}=\sum_{1}^{N} C \rho_{l} S \phi A_{c r} \Delta z
\end{array}\right\}
$$

The energy balance is given by:

$$
\begin{aligned}
& E_{i n}=\left.\int_{t_{1}}^{t_{2}} q_{c}^{\prime \prime}\right|_{z=0}+\left.\int_{t_{1}}^{t_{2}} q_{c a}^{\prime \prime \prime}\right|_{z=N}+\int_{z=0}^{z=L t_{1}} \int_{s o l}^{\prime \prime \prime} q_{s}^{\prime \prime \prime} d t d z \\
& \left.q_{c a}^{\prime \prime}\right|_{z=N}=\dot{m}_{e v p l}^{\prime \prime} / M_{v} * M_{a} C_{p a}\left(T_{a}-T_{0}\right) \\
& I . E=\left.\sum_{\text {phases }} \sum_{z=0}^{z=L}\left(\left(\rho C_{p}\right)_{\text {eff }}\left(T-T_{o}\right)\right)\right|_{t=t_{1}} \\
& E_{\text {out }}=\left.\int^{t_{2}}\left(q_{\text {cov }}^{\prime \prime}+q_{\text {rad }}^{\prime \prime}+q_{\text {evp }}^{\prime \prime}\right)\right|_{z=L} d t \\
& I . E=\sum_{\text {phases }} \sum_{z=0}^{z=L}\left(\left.\left(\rho C_{p}\right)_{e f f}\left(T-T_{o}\right)\right|_{t=t_{2}}\right.
\end{aligned}
$$

\section{Results}

The porous medium used in this analysis is sand of an average diameter of $0.63 \mathrm{~mm}$. The sand porosity is 0.3 . The sand permeability is $2.1 \times 10^{-11} \mathrm{~m}^{2}$ which is considered to be a high permeability [22]. The results of the model were obtained for Assuit location (longitude $31^{\circ} 10^{\prime} 58^{\prime \prime} E$ and latitude $27^{\circ} 10^{\prime} 58^{\prime \prime} N$ ) in a summer day (May 22- 2013) from 7:00 a.m. to 2:00 p.m. (solar time). The local solar noon is at 12:03:21. The maximum and minimum ambient temperatures are $311.15 \mathrm{~K}$ and $299.15 \mathrm{~K}$ and relative humidity is 0.4 at 3:00 p.m. These measurements were obtained from the meteorological data at website for Assuit location in Egypt [25]. The initial condition for liquid saturation, salt concentration and gas pressure are considered to be 0.99 , $0.035 \mathrm{~kg}_{\text {solute }} / \mathrm{kg}_{\text {solution }}$ and $101.325 \mathrm{kPa}$, respectively. The ambient temperature and vapor pressure at 7:00 a.m. estimated to be $302.2 \mathrm{~K}$ and $1.58 \mathrm{kPa}$, respectively, considered to be the initial temperature for the porous medium's components and the initial vapor pressure in the medium's gas.

Figures 6 to 10 show the results of the distributions of the five variables (saturation, concentration, pressure, temperature, vapor pressure) at different times. Figure 6 shows very slight decrease in liquid saturation in the porous medium at the first two hours. However, the saturation values decrease more as time passes almost linearly with $\mathrm{z}$ for the same time. The liquid saturation is relatively high in the distance from medium's center to the medium's bottom. The liquid saturation decreases at the front region mainly due to the vapor mass transfer to the surrounding. Wherever, the liquid saturation is decreased, the solar radiation penetrates more through medium thickness. This causes solar energy absorption to spread deeper to the interior region. The latter explains the increase in the evaporation rate by diffusion in the interior region. This is confirmed by the relatively large vapor pressure in the interior region as shown in Fig. 9 (water vapor pressure distribution curve).

Figure 7 shows the solution concentration profiles. It is clear that the maximum concentration values are at the upper region of the medium. The salt concentration is initially the same for the medium and by water evaporation the salt concentration increases. Firstly, the concentration is approximately taken the initial concentration value because the vapor pressure is approximately equal to the vapor saturation pressure. This leads to small diffusion of vapor from solution to gas for the interior region. At the top Region the concentration increases with increase in $\mathrm{z}$. At the last three hours, there is a relatively large difference in solution concentration between top and interior regions with the maximum concentration occurring at the surface. The soluble solute starts to crystallization at the hour 14 for $\mathrm{z}=\mathrm{L}$ since the supersaturation ratio has reached to a value of 2.6 and this value is larger than crystallization supersaturation ratio for sodium chloride (2.31) [26].

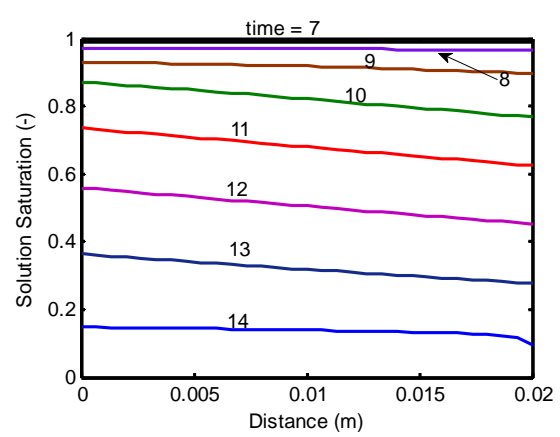

Fig 6. Saturation distribution -date 22/05/13;Time: 7:00-14:00

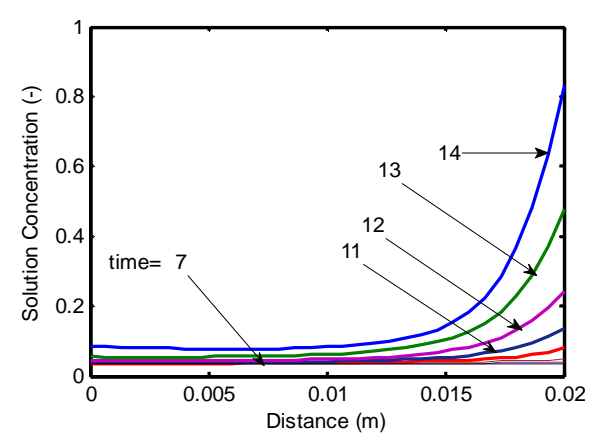

Fig 7. Concentration distribution-date 22/05/13; Time: 7:00- 14:00

In Fig. 8, the temperature profiles show that the maximum temperature is not at the surface. In the first two hours, the maximum temperature is at the top half region of the porous medium. However, for the following hours, the maximum temperature is at the bottom of the medium. The cooling effect at the surface causes its temperature to be always lower than that of the rest of the medium. The absorption coefficient for each of liquid and solid (sand) is larger than gas. Hence, as the liquid saturation decreases, the absorption 
coefficient decreases and the solar flux penetrates deeper in porous medium. This causes the maximum temperature to move deeper in the medium. The maximum temperatures occur at the hour 12 coping with time of almost maximum solar flux.

Figure 9 shows the partial water vapor pressure. The vapor pressure is changed at the end of each time interval according to the value of the stored vapor mass in the interval. In Fig. 9, it is clear that the water vapor pressure at surface node has lowest value due to diffusion of vapor to the atmospheric air. However, the surface pressure is changed from $1.58 \mathrm{kPa}$ to $5.0038 \mathrm{kPa}$ and the surface vapor pressure returns to reduce to $4.6402 \mathrm{kPa}$ at $13 \mathrm{p}$. m. It is generally clear from Fig. 9 that the water vapor pressure is mainly function of temperature which is responsible for increasing vapor mass by diffusion. The maximum value for vapor pressure is obtained at about the hour 12 (noon) at the bottom region of the medium. This is due to the maximum solar flux beside its deeper penetration in the medium. At this time the lowest vapor pressure is at the surface as expected and discussed before. It is also clear that the vapor gradient in the lower region of medium is relatively small at the first three hours and after that it increases with time till around solar noon. On the other hand, for top region there is always a pressure gradient that increases near the top and increases with time till solar noon. The results obtained for total vapor transferred to atmospheric air was about $8.3 \mathrm{~kg}$ for a time period of 7 hours.

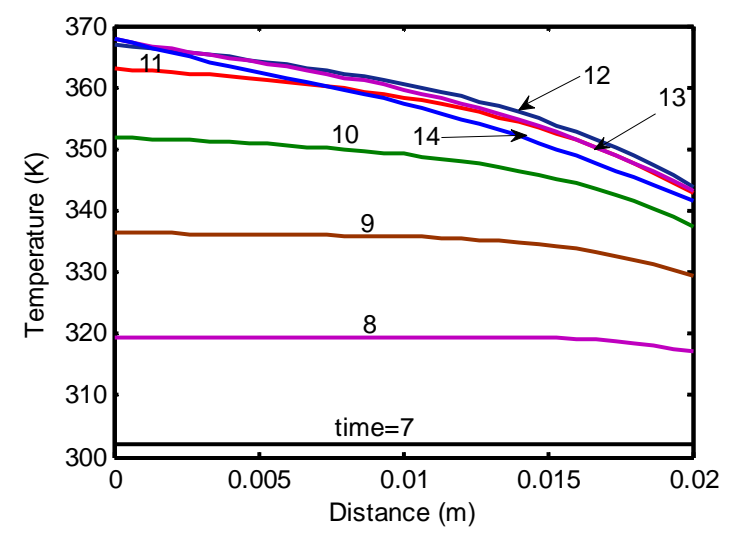

Fig 8. Temperature distribution-date 22/05/13; Time: 7:00- 14:00

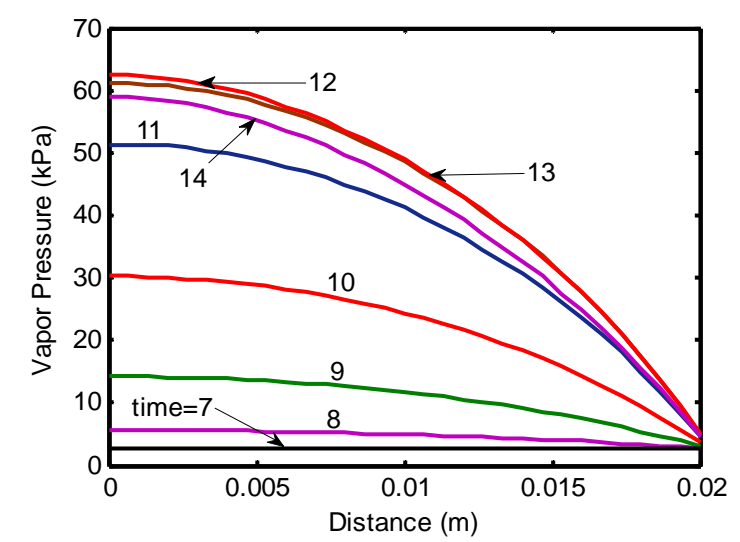

Fig 9. Water Vapor Pressure distribution-date 22/05/13; Time: 7:00-14:00
Figure 10 shows the total pressure profiles. It shows an increase in pressure in the first three hours especially in the interior region. The value of increase in total pressure is not exceeding $4 \mathrm{~Pa}$. At first hour, the gas relative permeability $K_{r g}$ is very small since $S_{l}$ is relatively large (Eq. 34). The gas capillary mass flux term is decreased as $K K_{r g} \frac{\partial P}{\partial z}$ is decreased leading to an increase in the stored mass of vapor and dry air (Eqs. 38 and 40, respectively). At the first three hours, especially for the interior region, the values of $K_{r g}$ and $\mathrm{K}$ are small since the liquid saturation is high (see Eq. 34). Also Fig. 10 shows that the total pressure gradient is small. Thus, $K K_{r z} \frac{\partial P}{\partial z}$ is small at the first hours; giving high storage terms for vapor and dry air. Hence, the pressure is relatively high at the first hours.

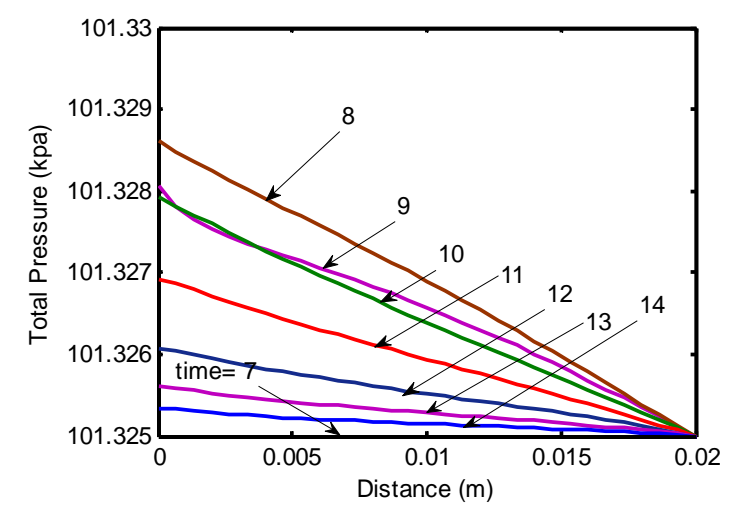

Fig 10. Pressure distribution - date 22/05/13; Time: 7:00- 14:00

\section{Conclusions}

The physical model takes into account the heat transfer mechanism, absorbed solar radiation; relative humidity and phase change inside the porous medium, the latter is the reason of building up water vapour pressure inside the medium. The solar radiation term is solved by considering it as energy generation in the elements's volumes. The mass transfer occurs in the liquid and vapor phases, each phase phenomenon is used alone to calculate the liquid saturation and water vapor pressure, respectively. The evaporative term is estimated and the water vapor pressure is calculated depending upon the physical phenomenon of water vapor mass transfer inside porous medium. The previous studies estimated the water vapor pressure using thermal equilibrium inside the porous medium thickness and the authors did not take into consideration the source term (evaporation term) of water vapor mass transfer inside the domain's elements. Whenever the surface water vapor pressure will be changed the inner water vapor pressures are affected. Then the water vapor mass in porous medium will be changed up or down according to the changing in surface vapor pressure. This scenario helps for controlling the phenomena of mass diffusion in porous medium in an opposite side of other studies which calculated the water vapor pressure from 
empirical equations. The change in ambient water vapor pressure affects the water vapor pressure inside the porous medium's elements. The previous studies did not take into consideration the salt concentration with water vapor pressure as variables. This porous medium system can be used with another system such as humid air region in solar still application and it has high dynamically response to the change in the water vapor pressure in the humid air region. The model's equation has taken highly nonlinearity and they strongly have linked, linearization of matrix coefficients is used. The coefficient matrix linearization is occurred by substituting the updated variables into it until the convergence criteria is occurred. Numerical solution gave converging results by applying mass and energy balances.

Table (1). Input constant data

\begin{tabular}{|c|c|c|c|c|c|c|c|}
\hline Parameter & Value & Unit & Source & Parameter & Value & Unit & Source \\
\hline Porosity $(\phi)$ & $0.37-0.5$ & - & [9] & Air molecular weight $\left(M_{a}\right)$ & 28.97 & $\mathrm{~kg} / \mathrm{kmol}$ & [4] \\
\hline Permeability $\left(K_{0}\right)$ & $\begin{array}{l}2 \times 10^{-11}- \\
1.8 \times 10^{-10}\end{array}$ & $m^{2}$ & [9] & Vapor molecular weight $\left(M_{v}\right)$ & 18.015 & $\mathrm{~kg} / \mathrm{kmol}$ & [4] \\
\hline Gas viscosity $\left(\mu_{g}\right)$ & $1.8 \times 10^{-5}$ & $\mathrm{~Pa}-\mathrm{s}$ & [1] & Salt diffusion coefficient $\left(D_{i}^{0}\right)$ & $1.5 \times 10^{-9}$ & $m^{2} / s$ & \\
\hline Ambient pressure $\left(P_{0}\right)$ & 101325 & $\mathrm{~Pa}$ & & Vapor diffusion coefficient $\left(D_{a v}\right)$ & $2.6 \times 10^{-5}$ & $m^{2} / s$ & \\
\hline Air kinematics viscosity $\left(v_{a}\right)$ & $1.6 \times 10^{\wedge}-5$ & $m^{2} / s$ & [8] & Irreducible saturation $\left(S_{i r}\right)$ & 0.08 & - & [9] \\
\hline Air thermal conductivity $\left(K_{a}\right)$ & 0.028 & $W /(m . K)$ & [8] & Initial temperature & $\mathrm{Ta}$ & $\mathrm{K}$ & \\
\hline $\begin{array}{l}\text { Vapor thermal conductivity } \\
\left(K_{v}\right)\end{array}$ & 0.0212 & $W /(m . K)$ & [8] & Initial Saturation $\left(S_{i}\right)$ & 0.99 & - & \\
\hline $\begin{array}{l}\text { Sand thermal conductivity } \\
\left(K_{s}\right)\end{array}$ & 0.27 & $W /(m . K)$ & [9] & Stefan-Boltzmann constant $(\sigma)$ & $5.67 \times 10^{-8}$ & $W /\left(m^{2} K^{4}\right)$ & [4] \\
\hline Sand density $\left(\rho_{s}\right)$ & 1530 & $\mathrm{~kg} / \mathrm{m}^{3}$ & & Sand emissivity $\left(\varepsilon_{s}\right)$ & 0.95 & - & \\
\hline Vapor specific heat $\left(C_{p v}\right)$ & 1410 & $J /(k g . K)$ & [8] & Gravity acceleration $(g)$ & 9.81 & $\mathrm{~m} / \mathrm{s}^{2}$ & \\
\hline Air specific heat $\left(C_{p a}\right)$ & 1004 & $J /(k g . K)$ & {$[14]$} & Pure water density $\left(\rho_{w}\right)$ & 998.2 & $\mathrm{~kg} / \mathrm{m}^{3}$ & {$[15]$} \\
\hline Sand specific heat $\left(C_{p s}\right)$ & 800 & $J /(k g \cdot K)$ & [4] & Sand absorption coefficient $\gamma_{s}$ & 60 & $m^{-1}$ & \\
\hline Salt specific heat $\left(C_{p, s a l}\right)$ & 850 & $J /(k g . K)$ & [27] & water absorption coefficient $\gamma_{l}$ & 350 & $m^{-1}$ & \\
\hline Vapor gas constant $\left(R_{v}\right)$ & 0.4615 & $k J /(k g . K)$ & [4] & vapor absorption coefficient $\gamma_{v}$ & 10 & $m^{-1}$ & \\
\hline Air gas constant $\left(R_{a}\right)$ & 0.287 & $k J /(k g . K)$ & [4] & Sand emissivity $(\varepsilon)$, & 0.95 & - & \\
\hline
\end{tabular}

\section{Nomenclature}

$A^{\prime}$

$\mathrm{C}$

c

$\left(C_{p}\right)_{e f f}$

$D_{\text {eff }}$,

$D_{\text {sal }}$

$D_{w}$

$q^{\prime \prime}$

$\vec{g}$

Gr

$\mathrm{h}$

$h_{c}$

$h_{m, v v}$

$h_{m l v}$

I.E supersaturation parameter

salt mass concentration ( $\mathrm{kg}$ of solute/ $\mathrm{kg}$ of solution)

phase content $\left(\mathrm{kg} / \mathrm{m}^{3}\right)$

effective specific heat

capacity $(k J / k g . K)$

effective-diffusivity $\left(\mathrm{m}^{2} / \mathrm{s}\right)$

salt diffusivity $\left(\mathrm{m}^{2} / \mathrm{s}\right)$

capillary diffusivity $\left(\mathrm{m} / \mathrm{s}^{2}\right)$

radiation flux $\left(\mathrm{W} / \mathrm{m}^{2}\right)$

gravity acceleration $\left(\mathrm{m} / \mathrm{s}^{2}\right)$

Grashof number;

enthalpy $(\mathrm{kJ} / \mathrm{kg})$

convictive heat transfer

coefficient $\left(W / m^{2} K\right)$

mass transfer coefficient inside porous medium $(\mathrm{m} / \mathrm{s})$

mass transfer coefficient from surface

porous medium $(\mathrm{m} / \mathrm{s})$

internal energy $\left(\mathrm{kJ} / \mathrm{m}^{3}\right)$
K

$K_{r, g}, K_{r, l}$

$K^{\prime}$

$L, L_{C}$

$\dot{m}^{\prime \prime}$

$\dot{m}_{e v p}^{\prime \prime \prime}$

$\dot{m}_{\text {prece }}^{\prime \prime \prime}$

$M_{a}, M_{v}$ air,

vapor

$\left(N u=\frac{h_{c} L_{c}}{K}\right)$

$P$

$\mathrm{P}$

$P_{c}, P_{v}$

$q_{r, 0}^{\prime \prime}$

$R_{j}$

$R h$ thermal conductivity $(\mathrm{kW} / \mathrm{m} . \mathrm{K})$ and intrinsic permeability $\left(\mathrm{m}^{2}\right)$

gas relative permeability (-), liquid relative permeability (-)

$\mathrm{NaCl}$ kinetic parameter

Porous medium thickness (m), characteristic length $(\mathrm{m})$ mass flux $\left(\mathrm{kg} / \mathrm{m}^{2} . \mathrm{s}\right)$

volumetric evaporation rate $\left(\mathrm{kg} / \mathrm{m}^{3} . \mathrm{s}\right)$ volumetric salt precipitation rate $\left(\mathrm{kg} / \mathrm{m}^{3} . \mathrm{s}\right)$

molar mass $(\mathrm{kg} / \mathrm{kmol})$

Nusselt number

gas pressure $(\mathrm{kPa})$

Precipitated salt

capillary pressure $(\mathrm{kPa})$, vapor pressure $(\mathrm{kPa})$

input solar flux $\left(W / \mathrm{m}^{2}\right)$

gas constant for gas $(k J / k g . K)$

relative humidity 


\begin{tabular}{|c|c|}
\hline$\left(S c=\frac{v}{D}\right)$ & Schmidt number. \\
\hline$\left(S h=\frac{h_{m} L_{c}}{D}\right)$ & Sherwood number; \\
\hline$S_{g}, S_{l}$ & gas saturation (-), liquid saturation (-) \\
\hline$S_{p}$ & precipitated salt saturation (-) \\
\hline$T, T_{S}$ & temperature $(\mathrm{K})$, sky temperature $(\mathrm{K})$ \\
\hline $\mathrm{V}$ & volume $\left(m^{3}\right)$ \\
\hline \multicolumn{2}{|l|}{ Greek Symbols } \\
\hline$\alpha$ & thermal diffusivity $\left(\mathrm{m}^{2} / \mathrm{s}\right)$ \\
\hline$\beta$ & volumetric thermal expansion $(1 / \mathrm{K})$ \\
\hline$\Delta$ & difference value \\
\hline$\gamma$ & absorption coefficient $(1 / \mathrm{m})$ \\
\hline$v$ & kinematic viscosity $\left(\mathrm{m}^{2} / \mathrm{s}\right)$ \\
\hline$\mu$ & dynamic viscosity $(\mathrm{kg} / \mathrm{m} . \mathrm{s})$ \\
\hline$w_{a}$ & humidity ratio of ambient air \\
\hline$w_{\text {sur }}$ & humidity ratio at medium surface. \\
\hline$\rho_{l}, \rho_{v}$ & $\begin{array}{l}\text { liquid density }\left(\mathrm{kg} / \mathrm{m}^{3}\right) \text {, Water vapor } \\
\text { density }\left(\mathrm{kg} / \mathrm{m}^{3}\right)\end{array}$ \\
\hline$\rho_{p}$ & salt crystal density $\left(\mathrm{kg} / \mathrm{m}^{3}\right)$ \\
\hline$\rho_{v s}$ & $\begin{array}{l}\text { vapor density of water vapor at } \\
\text { saturation }\left(\mathrm{kg} / \mathrm{m}^{3}\right)\end{array}$ \\
\hline$\phi$ & porosity (-) \\
\hline \multicolumn{2}{|l|}{ Symbols } \\
\hline$e q$ & equation \\
\hline$t$ & time \\
\hline \multicolumn{2}{|l|}{ Subscripts } \\
\hline$a$ & air \\
\hline$a m b$ & ambient \\
\hline$l$ & liquid \\
\hline$v$ & vapor \\
\hline sal & salt \\
\hline sat & sat \\
\hline tras & transparent \\
\hline eff & effective value \\
\hline cry & crystallization \\
\hline$s$ & sky \\
\hline sur & surface \\
\hline
\end{tabular}

\section{References}

[1] H. Ni, A. K. Datta and K. E. Torrance, Moisture transport in intensive microwave heating of biomaterials: a multiphase porous media model. International Journal of Heat and Mass Transfer, 42 (1999) 1501- 1512.

[2] A. Khodaparast and Haghi, Relations for water vapor transport through fibers. Journal of Computational and Applied Mechanics, 5 (2) (2004) 263- 274.

[3] V.A.F. Costa, M.L. Mendonca, and A.R. Figueiredo, Modeling and simulation of wetted porous thermal barriers operating under high temperature or high heat flux. International Journal of Heat and Mass Transfer; 51(2008) 3342-3354.

[4] A. Neale, D. Derome, B. Blocken and J. Carmerliet, Coupled
Simulation of Vapor Flow between Air and a Porous Material, ASHRAE, 2007.

[5] K. Murugesan, H. N. Suresh, K. N. Seetharamu, P. A. Aswatha Narayana and T. Sundararajan, A theoretical model of brick drying as a conjugate problem, International Journal of Heat and Mass Transfer, 44 (2001) 4075- 4086.

[6] H. Stephen Lee, Wallance W. Carr, Haskell W. Beckham, and Johannes Leisen, A model of through-air drying of tufted textile materials", International Journal of Heat and Mass Transfer, 45(2002) 357- 366.

[7] D. Le, H. Hoang, and J. Mahadevan, Impact of capillary driven liquid films on salt crystallization ". Transp. Porous Med, 80 (2009) 229-252.

[8] M. Koniorczyk, and D. Gawin, Numerical modeling of salt transport and precipitation in non-isothermal partially saturated porous media considering kinetics of salt phase changes. Transp. Porous Med, 87 (2011) 57-76.

[9] M. Kaviany, Principles of heat transfer in porous media, Handbook of Heat Transfer, Second edition, McGraw-Hill, New York, (1995) 2, 28, 479, 491.

[10] M. M. Elsayed, I. S. Taha, and J. A. Sabbagh, Design of Solar Thermal Systems. Scientific Publishing Centre; King Abdulaziz university, Saudi Arabia, (1994).

[11] D. Kraus, Two phase plow in homogenous porous media- The role of dynamic capillary pressure in modeling gravity driven fingering, Master's Thesis, 2011.

[12] Wikipedia, "Electromagnetic absorption by water" (http://en.wikipedia.org/wiki/Electromagnetic_absorption_by_ water)

[13] H. H. Li, "Absorption Coefficients", Int. J. Therm., Vol1, No. I, (1980).

[14] Y. A. Cengel, Heat and mass transfer", Hand book of Heat and Mass Transfer, Third edition, A practical approach, McGraw Hill, New York, 2006.

[15] M. Koniorczyk, Modelling the phase change of salt dissolved in pore water- Equilibrium and non-equilibrium approach, Construction and Building Materials, 24 (2010) 1119-1128.

[16] T.Q. Nguyen, J. Petkovic, P. Dangla and V. Baroghel-Bouny, Modeling of coupled ion and moisture transport in porous building materials, Construction and Building Materials (2007) $1-11$.

[17] J. Bear and A. Gilman, Migration of salts in the unsaturated zone caused by heating, Letters in Mathematical Physics, 19 (1995) 139-156.

[18] S. O. Pstalle, Non-isothermal multiphase flow of brine and gas through saline media, Doctoral-Barcelona, Universitat Politecnica de Catalunya, 1995.

[19] M.C. Boufadel, M.T. Suidan, and A.D. Venosa, Numerical modeling of water flow below dry salt lakes: effect of capillarity and viscosity, Journal of Hydrology, 221 (1999), $55-74$.

[20] A. Ramalingam and S. Arumugam, Experimental Study on Specific Heat of Hot Brine for Salt Gradient Solar Pond Application, International Journal of Chem. Tech Research, 4 (3) (2012), 956-961. 
[21] A. Haldera and A. K. Dattab, Surface heat and mass transfer coefficients for multiphase porous media transport models with rapid evaporation, Food and Bio-products Processing, 90(2012) 475-490.

[22] V.A.F. Costa, M.L. Mendonca and A.R. Figueiredo, "Modeling and simulation of wetted porous thermal barriers operating under high temperature or high heat flux". International Journal of Heat and Mass Transfer; Vol. 51; 2008; 3342-3354.

[23] G. F. Pinder, W. G. Gray, Essentials of multiphase flow and transport in porous media, A John Wiley \& Sons, Inc., Hoboken, New Jersey, 2008.
[24] S. V. Patankar, Numerical heat transfer and fluid flow, Book, Publishers, Talyor \& Francis, 1980.

[25] Website of " Egyptian meteorological Authority " (http://ema.gov.eg/articles?menu=62\&lang=eg)

[26] H. Na, S. Arnold, and A. S. Myerson, Cluster formation in highly supersaturated solution droplets, Journal of Crystal Growth, 139 (1994) 104-112.

[27] W. Scott Pegau, Deric Gray, and J. Ronald V. Zaneveld, Absorption and attenuation of visible and near-infrared light in water: dependence on temperature and salinity, Applied Optics, 36 (24) (1997) 6035- 646. 